\title{
PERAN JOB SATISFACTION SEBAGAI VARIABEL INTERVENING ANTARA WORK LIFE BALANCE TERHADAP EMPLOYEE PERFORMANCE
}

\author{
Mei Wulandari \\ Universitas Negeri Surabaya \\ mei.17080574046@mhs.unesa.ac.id \\ Hafid Kholidi Hadi \\ Universitas Negeri Surabaya \\ hafidhadi@unesa.ac.id
}

\begin{abstract}
PDAM Giri Tirta of Gresik Regency is a Regional Owned Enterprise engaged in distributing clean water to all areas of Gresik Regency to meet the basic needs of clean water for all communities. The impact of the pandemic's environmental change has affected the work-life of employees and has an impact on the level of job satisfaction and employee performance. This study aimed to determine and explain how work-life balance affects employee performance through job satisfaction as an intervening variable. This research is a type of quantitative research. The object of the research at PDAM Giri Tirta, Gresik Regency, Menganti Branch. Sampling technique using the saturated technique, namely all populations of the research object, totalling 32 employees as the research sample. This study uses Partial Least Square (PLS) analysis with the help of SmartPLS 3.3.2 software. The results showed that work-life balance had a significant positive effect on employee performance. Work-life balance has a significant positive effect on job satisfaction. Job satisfaction has no significant effect but is positively related to employee performance, and work-life balance does not significantly affect employee performance through job satisfaction. So that job satisfaction does not have a mediating role between work-life balance and employee performance.
\end{abstract}

Keywords: employee performance; job satisfaction; work-life balance

\section{PENDAHULUAN}

Tantangan perusahaan di era revolusi industri 4.0 menjadi sangat dinamis, dipengaruhi berbagai perubahan lingkungan. Peran teknologi mendorong tingkat pertumbuhan industri berkembang pesat (Susanto, 2019). Pertumbuhan industri tersebut menuntut perusahaan berdaya saing tinggi supaya dapat memertahankan eksistensinya. Salah satu perusahaan yang menuntut persaingan cukup kuat yaitu perusahaan penyedia air minum daerah, yang biasa disebut Perusahaan Daerah Air Minum (PDAM). PDAM Giri Tirta Kabupaten Gresik merupakan Badan Usaha Milik Daerah (BUMD) yang bertanggung jawab melakukan pendistribusian air bersih pada seluruh wilayah Kabupaten Gresik, guna memenuhi kebutuhan masyarakat akan air bersih layak konsumsi (PDAM Giri Tirta, 2016).

Sesuai dengan Undang-Undang tentang Sumber Daya Air Nomor 7 Tahun 2004, bahwa tanggung jawab pengembangan sistem penyediaan air minum merupakan tugas Pemerintah dan Pemerintah Daerah, di mana diselenggarakan untuk mewujudkan kesejahteraan masyarakat dalam menjamin kebutuhan dasar akan air minum dengan memenuhi standar dan syarat akan kualitas, kuantitas, juga kontinuitas (Undang-Undang RI, 2004). Oleh sebab itu perlu perbaikan pelayanan pelanggan untuk memenuhi tuntutan dan persaingan perusahaan. Strategi yang dapat digunakan untuk memenuhi tuntutan tersebut yakni mengelola Sumber Daya Manusia (SDM) yang ada dengan memerhatikan setiap kebutuhannya, karena perusahaan harus menyadari dengan benar bahwa kualitas SDM yang baik dapat berpengaruh pada peningkatan kinerja terutama dalam memberikan pelayanan untuk pelanggan.

Pekerjaan karyawan PDAM Giri Tirta dapat dikatakan cukup kompleks karena berhubungan langsung dengan pelanggan dengan berbagai tipe dan pekerjaan tidak hanya terpusat pada kantor, tetapi juga memiliki tanggung jawab untuk langsung terjun ke lapangan dalam melayani pelanggan. Terutama dengan adanya pandemi beberapa waktu terakhir menambah beban para karyawan khususnya bagi 
Mei Wulandari \& Hafid Kholidi Hadi. Peran Job Satisfaction sebagai Variabel Intervening antara Work Life Balance terhadap Employee Performance

karyawan yang telah menjadi orang tua, juga yang menjalankan kerja bersamaan kuliah dikhawatirkan dapat menganggu kinerjanya, sehingga dibutuhkan work life balance yang baik. Tetapi diketahui dugaan sementara dari hasil observasi lapangan dan wawancara, adanya pekerjaan yang cukup padat juga kondisi pandemi yang membuat semua aktivitas tidak normal, tidak membuat kinerja karyawan menjadi berantakan. Dibuktikan dengan target-target perusahaan yang tercapai terutama pada subbagian pelayanan pelanggan pada penagihan dan eksekusi seperti pencapaian target kerja minimal $80 \%$ untuk penutupan sementara meteran air pelanggan yang menunggak pembayaran dan telah diberikan surat tagihan sebelumnya dalam setiap akhir bulan, ini dilakukan sesuai standar mutu dan prosedur perusahaan, meskipun memang terdapat perbedaan pada subbagian distribusi dan gangguan dalam kepuasan kerja yang dirasa kurang akibat perbedaan deskripsi pekerjaan dengan jam lembur kerja lebih padat yakni lebih dari 14 jam perminggu. Diduga hal ini disebabkan oleh work life balance yang diberikan perusahaan. Dari adanya work life balance tersebut menimbulkan kepuasan kerja atau job satisfaction, di mana kepuasan kerja ini yang memengaruhi tingkat employee performance atau kinerja karyawan PDAM Giri Tirta Kabupaten Gresik Cabang Menganti.

Menurut Muliawati \& Frianto (2020), work life balance adalah keseimbangan kehidupan seorang individu untuk dapat menjalankan dua peran atau lebih dalam membagi waktu antara pekerjaan, kehidupan pribadi, maupun untuk keluarga. Work life balance dapat mengurangi konflik antara kehidupan pribadi juga pekerjaan, sehingga menjadikan karyawan lebih efektif dalam bekerja (Nirmalasari, 2018). Menurut Wambui et al. (2017), keseimbangan kehidupan kerja yang tidak memadahi akan menimbulkan risiko besar terhadap kesejahteraan karyawan terutama dalam kinerja karyawan maupun organisasi. Pengaruh work life balance terhadap meningkatnya employee performance dapat dibuktikan melalui penelitian dari Soomro et al. (2018), Wambui et al. (2017), Obiageli et al. (2015), bahwa work life balance berpengaruh secara positif terhadap employee performance. Sedangkan hasil penelitian dengan pendapat lain disampaikan oleh Keino \& Kithae (2016), mengatakan bahwa work life balance berpengaruh signifikan negatif terhadap employee performance.

Work life balance juga memiliki pengaruh terhadap kepuasan kerja atau job satisfaction, di mana program keseimbangan antara peran kehidupan pribadi dan pekerjaan yang diberikan organisasi atau perusahaan akan berdampak pada kepuasan kerja karyawan (Burke, 2000 dalam Nirmalasari, 2018). Pengaruh work life balance terhadap job satisfaction dibuktikan melalui penelitian Machuca et al. (2016), Shoba \& Suganthi, (2019), Pathak et al. (2019), Maslichah \& Hidayat (2017), Auranzeb \& Bhutto (2016), Anuradha \& Pandey (2016) bahwa work life balance memiliki pengaruh positif dan signifikan terhadap kepuasan kerja atau job satisfaction. Namun Ganapathi (2016) membuktikan bahwa work life balance tidak berpengaruh secara parsial terhadap kepuasan kerja. Son \& Jung (2019) menyatakan work life balance memiliki pengaruh signifikan negatif terhadap job satisfaction.

Kepuasan kerja atau job satisfaction memiliki dampak yang cukup besar dalam meningkatkan kinerja karyawan suatu perusahaan, hal ini sesuai pendapat Rene \& Wahyuni (2018), bahwa karyawan yang merasa puas dengan pekerjaannya cenderung menunjukkan keterlibatan yang lebih dalam organisasi yang mana hal ini menyangkut dengan kinerja Isse et al. (2018), dan Yuen et al. (2018) menyatakan bahwa job satisfaction berpengaruh positif dan signifikan terhadap employee performance. Tetapi menurut Bataineh (2019) job satisfaction tidak berdampak signifikan terhadap employee performance.

Penelitian ini menggunakan variabel mediasi atau intervening berupa job satisfaction. Penggunaan job satisfaction sebagai variabel intervening dikarenakan kepuasan kerja tidak dapat terjadi begitu saja, melainkan melalui suatu sebab seperti adanya work life balance yang baik, kemudian menimbulkan rasa nyaman dalam bekerja. Rasa nyaman tersebut yang membuat seseorang lebih puas akan pekerjaan mereka, sehingga dapat memotivasi meningkatkan kinerja (Herlambang \& Murniningsih, 2019). Penjelasan tersebut menunjukkan bahwa job satisfaction timbul akibat adanya pengaruh suatu faktor atau variabel lain, yang kemudian menghasilkan pengaruh baru, di mana adanya work life balance menyebabkan job satisfaction terbentuk, lalu job satisfaction tersebut menghasilkan pengaruh baru terhadap karyawan berupa perubahan kinerja atau employee performance. 
Pengaruh kepuasan sebagai peran mediasi dibuktikan oleh Herlambang \& Murniningsih (2019), dan Dousin et al. (2019) bahwa kepuasan kerja atau job satisfaction memiliki pengaruh signifikan positif terhadap kinerja, dan mempunyai peran memediasi work life balance terhadap kinerja karyawan atau employee performance. Hal tersebut didukung oleh Mendis \& Weerakkody (2018) bahwa work life balance secara positif mengarah pada kinerja karyawan yang lebih tinggi melalui kepuasan kerja karyawan. Meskipun terdapat pendapat lain yang berbeda disampaikan oleh Soomro et al. (2018) bahwa kepuasan kerja hanya sebagai pendukung untuk memerkuat ataupun memerlemah pengaruh kinerja karyawan, yang biasa disebut sebagai variabel moderasi.

Objek penelitian dilakukan pada Perusahaan Daerah Air Minum (PDAM) Giri Tirta Kabupaten Gresik Cabang Menganti dengan melibatkan semua karyawan. Pemilihan objek pada PDAM dengan memertimbangkan job description yang kompleks di mana tidak hanya terpaku pada tugas di dalam kantor saja, tetapi pekerjaan juga mengharuskan turun ke lapangan langsung berhubungan dengan pelanggan. Ditambah kondisi lingkungan yang kurang stabil akhir-akhir ini akibat adanya pandemi menyebabkan tugas atau tanggung jawab karyawan semakin bertambah terutama bagi mereka yang bekerja dengan kuliah, juga karyawan yang telah memiliki keluarga dan memiliki tanggung jawab tambahan kepada anaknya. Sehingga adanya fenomena tersebut menuntut perusahaan untuk memerhatikan work life balance karyawan agar kepuasan kerja terjaga dan berdampak pada peningkatan employee performance ketika job satisfaction yang dimiliki karyawan tinggi.

Berdasarkan fenomena dan riset gap, maka penelitian ini memiliki tujuan untuk menganalisis bagaimana pengaruh peran job satisfaction sebagai variabel intervening antara work life balance terhadap employee performance pada PDAM Giri Tirta Kabupaten Gresik Cabang Menganti.

\section{KAJIAN PUSTAKA DAN PENGEMBANGAN HIPOTESIS}

\section{Work Life Balance}

Work life balance didefinisikan kepuasan serta kemampuan karyawan dalam menjalankan peran dengan baik di keluarga dan tempat kerja, serta meminimalisir konflik di antara keduanya (Clark, 2000). Sedangkan menurut Fisher et al. (2009) work life balance yakni sebagai upaya penyeimbangan dua peran atau lebih yang dijalani oleh individu. Pengertian lain dikemukakan Greenhaus et al. (2003) yang mana work life balance didefinisikan sebagai rasa puas dan keterikatan individu terhadap kemampuan menyeimbangkan tuntutan pekerjaan dan keluarga. Hal ini sejalan dengan pendapat Lockwood (2003) di mana work life balance merupakan kondisi di mana karyawan dapat menyeimbangkan antara dua tuntutan yaitu tuntutan pekerjaan dan kondisi individu dirinya. Berdasarkan pendapat beberapa pengertian di atas, maka makna work life balance merupakan kondisi di mana karyawan dapat menyeimbangkan antara peran kehidupan kerja dan pribadi atau keluarga, tanpa harus mengorbankan salah satunya sehingga menimbulkan kepuasan serta keterikatan pada diri karyawan.

Penelitian ini menggunakan indikator dari Greenhaus et al. (2003) karena kasus work life balance yang terjadi meliputi hal-hal yang telah disebutkan pada penelitian sebelumnya. Fenomena work life balance sesuai dengan indikator dari Greenhaus et al. (2003) yaitu keseimbangan waktu, keseimbangan keterlibatan, dan keseimbangan kepuasan.

\section{Job Satisfaction}

Menurut Luthans (2011) job satisfaction yaitu sebagai hasil persepsi karyawan mengenai seberapa baik pekerjaannya yang dinilai penting. Sedangkan menurut Sidik (2019) job satisfaction didefinisikan sebagai perasaan positif mengenai hasil pekerjaan seseorang, yang mana tingkat kepuasan kerja yang tinggi akan memengaruhi tingkat perasaan positif tentang pekerjaan tersebut. Hal ini sejalan dengan pengertian menurut Robbins \& Judge (2008), job satisfaction merupakan perasaan positif mengenai suatu pekerjaan dari hasil evaluasi pekerjaan tersebut. Di mana ketika tingkat kepuasan kerja tinggi maka seseorang akan memiliki perasaan positif mengenai pekerjaannya, sebaliknya seseorang dengan kepuasan kerja rendah cenderung memiliki perasaan negatif terhadap 
Mei Wulandari \& Hafid Kholidi Hadi. Peran Job Satisfaction sebagai Variabel Intervening antara Work Life Balance terhadap Employee Performance

pekerjaannya. Sedangkan menurut As'ad (2004) job satisfaction didefinisikan sebagai suatu sikap positif menyangkut penyesuaian diri yang sehat oleh karyawan terhadap kondisi dan situasi kerja. Dari berbagai definisi kepuasan kerja di atas, maka job satisfaction merupakan perasaan positif terhadap hasil kerja yang dilakukan, penyesuaian diri, kondisi kerja, maupun situasi yang mana hal tersebut sesuai dengan harapan karyawan.

Penelitian ini menggunakan indikator dari As'ad (2004), yang mana indikator tersebut sesuai dengan kasus kepuasan kerja yang ada pada kondisi perusahaan tempat penelitian. Adapun indikator tersebut meliputi faktor fisik, faktor psikologis, dan faktor sosial.

\section{Employee Performance}

Kinerja karyawan atau employee performance menurut Hasibuan (2003) didefinisikan sebagai hasil kerja yang dicapai seseorang dalam melaksanakan tugas-tugas yang dibebankan kepadanya didasarkan atas ketepatan, pengalaman, dan kesungguhan dalam bekerja. Hal ini didukung oleh Mangkunegara (2009) dengan menambahkan pengertian bahwa yang dimaksud hasil kerja yaitu termasuk di dalamnya kualitas dan kuantitas yang dicapai seorang karyawan ketika melaksanakan tugas sesuai dengan tanggung jawab yang diberikan. Sejalan dengan pendapat di atas, menurut Nurwahyuni (2019), employee performance merupakan suatu keberhasilan yang dicapai karyawan berdasar pada kegiatan yang dilaksanakan karyawan dalam menjalankan pekerjaannya. Sedangkan menurut Mathis \& Jackson (2006) employee performance merupakan apa yang dilakukan atau tidak dilakukan oleh karyawan. Selain itu kinerja juga berkaitan dengan melaksanakan atau menyempurnakan tanggung jawab (Rivai, 2005). Berdasarkan pengertian dari beberapa ahli di atas maka employee performance merupakan hasil dari apa yang dilakukan atau tidak dilakukan karyawan dalam menyelesaikan tugas yang menjadi tanggung jawabnya didasarkan pada kualitas, kuantitas, ketepatan waktu, kemampuan bekerja sama, dan kehadiran. Indikator yang digunakan berasal dari Mathis \& Jackson (2006) di antaranya: kuantitas dari hasil, kualitas dari hasil, ketepatan waktu dari hasil, dan kehadiran.

\section{Hubungan antar Variabel}

Keseimbangan kehidupan kerja atau work life balance memiliki pengaruh penting dalam peningkatan employee performance. Keseimbangan kehidupan kerja yang tidak memadai akan menimbulkan masalah dan risiko besar terhadap kesejahteraan pekerjaan yang mana akan memengaruhi kinerja karyawan serta kinerja organisasi (Wambui et al., 2017). Obiageli et al. (2015) menyatakan bahwa work life balance berpengaruh signifikan positif terhadap employee performance. Hal tersebut didukung Soomro et al. (2018) bahwa work life balance berpengaruh signifikan positif terhadap kinerja karyawan, di mana karyawan usia muda mampu menemukan keseimbangan yang cocok untuk pekerjaan dan komitmen keluarga sehingga meningkatkan produktivitas dalam organisasi. Wambui et al. (2017), dengan hasil work life balance berpengaruh signifikan positif terhadap employee performance, hasil tersebut menjelaskan umumnya karyawan merasa kehidupan kerja atau konflik keluarga dapat menjadi sumber stres dan akan memengaruhi kinerja mereka.

H1 : Work life balance berpengaruh signifikan positif terhadap employee performance.

Work life balance merupakan keseimbangan kehidupan di dalam pekerjaan yang merupakan faktor penting yang dapat mendukung peningkatan kepuasan kerja terhadap pekerjaan seseorang (Maslichah \& Hidayat, 2017). Seseorang yang memiliki keseimbangan antara pekerjaan dan kehidupan pribadi yang tinggi cenderung lebih puas, daripada harus mengorbankan salah satu dari keduanya. Pengaruh work life balance terhadap job satisfaction dibuktikan oleh Shoba \& Suganthi (2019), yang menyatakan berpengaruh signifikan positif. Di mana dapat diindikasikan melalui pengaturan kerja yang fleksibel dan sikap dari pekerja tersebut. Karena pekerjaan yang fleksibel akan memungkinkan seorang karyawan memiliki waktu yang cukup untuk dibagi dengan kehidupan pribadi, keluarga, maupun untuk mengurus diri sendiri. Hasil ini didukung oleh Machuca et al. (2016) bahwa work life balance memiliki pengaruh positif terhadap job satisfaction.

$\mathrm{H} 2$ : Work life balance berpengaruh signifikan positif terhadap job satisfaction. 
Kepuasan merupakan tolok ukur pertama yang berpengaruh besar terhadap peningkatan kinerja. Hal ini disebabkan seseorang yang memiliki job satisfaction tinggi maka mereka akan secara suka rela memberikan yang terbaik versi dirinya kepada perusahaan, hal tersebut berkaitan dengan kinerja karyawan itu sendiri (Rene \& Wahyuni, 2018). Isse et al. (2018), menyatakan job satisfaction berpengaruh positif terhadap employee performance. Standar kepuasan kerja akan meningkatkan kinerja menjadi lebih tinggi. Kepuasan kerja merupakan unsur intrinsik dan ekstrinsik, di mana ketika tingkat kepuasan ditingkatkan maka karyawan akan bekerja lebih keras lagi. Faktor intrinsik akan memainkan peran ketika seorang karyawan tersebut mendapat apresiasi dari manajemen, maka mereka cenderung termotivasi dan mentransfer motivasi tersebut untuk bekerja lebih keras sehingga meningkatkan prestasi kerja atau employee performance.

\section{H3 : Job satisfaction berpengaruh signifikan positif terhadap employee performance.}

Praktik work life balance sangat penting dalam menentukan pekerjaan karyawan, kinerja juga kepuasannya. Ketika seorang memiliki kepuasan yang tinggi akan work life balancenya, maka akan berpengaruh secara langsung terhadap peningkatan kinerjanya (Dousin et al., 2019). Diketahui bahwa pengaruh work life balance tidak dapat terjadi secara langsung, melainkan melalui perantara job satisfaction untuk bisa mempengaruhi employee performance, hal ini dikarenakan job satisfaction terjadi karena rasa nyaman seseorang dalam menjalani pekerjaannya, rasa nyaman ini dapat terjadi karena adanya sarana prasarana yang menunjang dalam bekerja, terutama work life balance yang diberikan perusahaan kepada karyawan (Herlambang \& Murniningsih, 2019).

Job satisfaction dalam perannya sebagai variabel mediasi dipengaruhi adanya faktor motivasi intrinsik dan ekstrinsik, di mana meliputi hubungan sosial dengan kelompok kerja, kualitas pengawasan, dan seberapa jauh keberhasilan individu dalam bekerja (Mendis \& Weerakkody, 2018). Selain itu penelitian Herlambang \& Murniningsih (2019) juga membuktikan peran job satisfaction memediasi antara work life balance terhadap employee performance, di mana dalam hal ini kinerja karyawan dalam perusahaan dapat dikatakan baik ketika memiliki keseimbangan antara kehidupan dan pekerjaan untuk karyawannya, sehingga menimbulkan kepuasan dan berdampak pada peningkatan kinerja akibat kepuasan yang dirasakan tersebut.

H4 : Job satisfaction memediasi work life balance terhadap employee performance.

\section{METODE PENELITIAN}

Penelitian ini merupakan jenis penelitian kuantitatif. Penelitian dilakukan pada PDAM Giri Tirta Kabupaten Gresik Cabang Menganti, yang bertempat di Jl.Raya Bringkang, Mojotengah, Kecamatan Menganti, Kabupaten Gresik. Populasi yang digunakan adalah seluruh karyawan PDAM Giri Tirta Kabupaten Gresik Cabang Menganti. Pengambilan sampel meggunakan teknik sampel jenuh, di mana semua anggota populasi diambil menjadi sampel penelitian, yakni seluruh karyawan berjumlah 32 orang, yang meliputi: 1 kepala cabang; 2 kepala subbagian (subbagian pelayanan pelanggan, dan subbagian distribusi gangguan); 4 staf eksekusi dan penagihan, 2 staf hubungan pelanggan; 2 staf keuangan atau kasir; 14 staf cek meter; dan 6 staf teknik.

Penelitian menggunakan tiga jenis variabel yang meliputi: work life balance sebagai variabel independen (X), employee performance sebagai variabel dependen (Y), dan job satisfaction sebagai variabel mediasi atau intervening $(Z)$. Teknik pengumpulan data dilakukan melalui penyebaran kuesioner secara offline dengan memberikan hardfile berisi item pertanyaan dan data diri karyawan, observasi kondisi lapangan, serta wawancara dengan karyawan. Skala pengukuran yang digunakan pada kuesioner yaitu skala likert 1 sampai 5, yang dikategorikan dari sangat tidak setuju, tidak setuju, netral, setuju, dan sangat setuju.

Sumber data yang digunakan yaitu sumber data primer didapatkan langsung dari hasil pengisian kuesioner, serta hasil wawancara sebagai data pendukung; dan sumber data sekunder berasal dari 
Mei Wulandari \& Hafid Kholidi Hadi. Peran Job Satisfaction sebagai Variabel Intervening antara Work Life Balance terhadap Employee Performance

literatur ataupun sumber-sumber lain untuk pertimbangan pengambilan keputusan maupun penentuan gambaran dalam analisis data. Data dianalisis dengan metode Partial Least Square (PLS) melalui analisis uji validitas dan uji reliabilitas dengan bantuan software smartPLS 3.3.2, karena smartPLS cocok digunakan untuk pengujian sampel kecil.

\section{HASIL DAN PEMBAHASAN}

\section{Hasil Uji Validitas}

Uji validitas untuk melihat seberapa baik atau valid covergent validity, yang mana dapat diketahui dari nilai outer loading masing-masing item indikator harus di atas 0,70 agar dapat dikatakan valid. Berdasarkan output smartPLS pada tabel 1, hasil uji validitas semua outer loadings pada masingmasing variabel dinilai valid karena memiliki nilai di atas 0,70 .

Tabel 1.

OUTER LOADING VARIABEL

\begin{tabular}{lcc}
\hline Item & Outer Loading & Keterangan \\
\hline X1.1.1 & 0,889 & Valid \\
X1.1.2 & 0,845 & Valid \\
X1.1.3 & 0,854 & Valid \\
X1.2.1 & 0,859 & Valid \\
X1.2.2 & 0,749 & Valid \\
X1.2.3 & 0,710 & Valid \\
X1.3.1 & 0,775 & Valid \\
X1.3.2 & 0,849 & Valid \\
X1.3.3 & 0,774 & Valid \\
Y1.1.1 & 0,775 & Valid \\
Y1.1.2 & 0,845 & Valid \\
Y1.2.1 & 0,903 & Valid \\
Y1.2.2 & 0,846 & Valid \\
Y1.3.1 & 0,810 & Valid \\
Y1.3.2 & 0,889 & Valid \\
Y1.4.1 & 0,884 & Valid \\
Y1.4.2 & 0,805 & Valid \\
Z1.1.1 & 0,787 & Valid \\
Z1.1.2 & 0,771 & Valid \\
Z1.1.3 & 0,884 & Valid \\
Z1.2.1 & 0,893 & Valid \\
Z1.2.2 & 0,889 & Valid \\
Z1.3.1 & 0,871 & Valid \\
Z1.3.2 & 0,835 & Valid \\
Z1.3.3 & 0,831 & Valid \\
Z1.3.4 & 0,771 & Valid \\
\hline Sunb & Out &
\end{tabular}

Sumber: Output SmartPLS 3.3.2 (2021)

\section{Hasil Uji Reliabilitas}

Uji reliabilitas berguna untuk mengetahui sejauh mana hasil pengukuran tetap konsisten digunakan. Dapat dilihat dari nilai composite reliability dan nilai cronbach's alpha masing-masing, di mana nilai harus di atas 0,70 agar model variabel dikatakan baik. Berdasarkan tabel 2, nilai composite reliability dan nilai cronbach's alpha tiap-tiap variabel di atas 0,70. Maka dapat dijelaskan bahwa model variabel sudah baik dan reliabel. 
Tabel 2.

COMPOSITE RELIABILITY DAN CRONBACH'S ALPHA

\begin{tabular}{lcc}
\hline \multicolumn{1}{c}{ Variabel } & Composite Reliability & Cronbach's Alpha \\
\hline Work life balance & 0,946 & 0,935 \\
Employee performance & 0,952 & 0,943 \\
Job satisfaction & 0,955 & 0,947 \\
\hline
\end{tabular}

Sumber: Output SmartPLS 3.3.2 (2021)

\section{Hasil Uji R-Square}

Uji $R$-Square digunakan untuk menujukkan model pengaruh variabel independen terhadap variabel dependen. Nilai $R$-Square pada variabel job satisfaction sebesar 0,848. Maka variabel konstruk job satisfaction mampu dijelaskan oleh variabel work life balance sebesar $85 \%$ sedangkan variabelvariabel lain yang tidak terdapat dalam penelitian mampu menjelaskan job satisfaction pada karyawan PDAM Giri Tirta Kabupaten Gresik Cabang Menganti sebesar 15\%.

Nilai $R$-Square variabel employee performance sebesar 0,891. Maka variabel konstruk employee performance dapat dijelaskan oleh variabel work life balance sebesar $89 \%$, sisanya dijelaskan oleh variabel-variabel lain sebesar $11 \%$ dapat mengukur employee performance PDAM Giri Tirta Kabupaten Gresik Cabang Menganti.

\section{Hasil Uji Kausalitas}

Uji kausalitas berguna untuk mengetahui hubungan antar konstruk dan nilai signifikansi pengaruh antar variabel. Nilai original sampel menunjukkan arah hubungan antar konstruk atau variabel, di mana nilai angka positif menunjukkan arah hubungan variabel positif, dan nilai negatif menunjukkan arah hubungan yang negatif. Sedangkan nilai $T$-statistics menunjukkan signifikansi antar variabel, di mana nilai $T$-statistics dibawah 1,96 maka tidak signifikan atau tidak ada pengaruh antar variabel.

Berdasarkan tabel 3, hubungan antar variabel memiliki arah hubungan yang positif. Terdapat dua hubungan antar variabel yang berpengaruh signifikan dan dua lagi hubungan antar variabel yang tidak berpengaruh signifikan. Variabel yang berpengaruh signifikan yakni pada work life balance terhadap employee performance, dan work life balance terhadap job satisfaction. Sedangkan yang tidak berpengaruh signifikan yaitu job satisfaction terhadap employee performance, dan work life balance terhadap employee performance melalui job satisfaction.

Tabel 3.

\section{DIRECT EFFECT DAN INDIRECT EFFECT}

\begin{tabular}{lcccc}
\hline \multicolumn{1}{c}{ Hubungan antar Variabel } & Original Sampel & T-Statistics & Keterangan & Keputusan \\
\hline $\begin{array}{l}\text { Work Life Balance } \rightarrow \text { Employee } \\
\text { Performance }\end{array}$ & 0,678 & 4,320 & Signifikan & Hipotesis Diterima \\
$\begin{array}{l}\text { Work Life Balance } \rightarrow \text { Job } \\
\text { Satisfaction }\end{array}$ & 0,921 & 35,999 & Signifikan & Hipotesis Diterima \\
$\begin{array}{l}\text { Job Satisfaction } \rightarrow \text { Employee } \\
\text { Performance }\end{array}$ & 0,282 & 1,728 & Tidak signifikan & Hipotesis Ditolak \\
$\begin{array}{l}\text { Work Life Balance } \rightarrow \text { Job } \\
\text { Satisfaction } \rightarrow \text { Employee }\end{array}$ & 0,260 & 1,704 & Tidak signifikan & Hipotesis Ditolak \\
Performance & & & & \\
\hline Sumber: Output SmartPLS3.20 & & & \\
\hline
\end{tabular}

Sumber: Output SmartPLS 3.3.2 (2021)

\section{Pengaruh Work Life Balance terhadap Employee Performance}

Dari hasil pengujian diketahui bahwa work life balance memiliki pengaruh signifikan positif terhadap employee performance, sehingga $\mathrm{H} 1$ diterima. Hasil penelitian memerkuat penelitian Wambui et al. (2017) bahwa work life balance berpengaruh signifikan positif terhadap employee performance. 
Mei Wulandari \& Hafid Kholidi Hadi. Peran Job Satisfaction sebagai Variabel Intervening antara Work Life Balance terhadap Employee Performance

Variabel yang digunakan dalam penelitian tersebut yaitu work life balance, program bantuan karyawan, dan employee performance. Work life balance yang dimaksudkan yakni prioritas antara pekerjaan dan keluarga. Menurut Wambui et al. (2017), ketika pekerjaan dan prioritas keluarga bertentangan hal ini memengaruhi kinerja karyawan. Karyawan umumnya merasa kehidupan kerja dan konflik keluarga adalah sumber stres, yang mana ketika terjadi konflik keluarga atau pekerjaan akan mengganggu kesejahteraan dan produktivitas secara keseluruhan juga menurunkan komitmen dalam bekerja.

Jika dikaitkan dengan penelitian yang dilakukan di PDAM Giri Tirta Cabang Menganti, tingginya keseimbangan kehidupan kerja yang diberikan melalui keseimbangan waktu kerja, seperti jam kerja yang tidak lebih dari 40 jam perminggu, jam lembur tidak lebih dari 14 jam perminggu dan waktu untuk menjalankan kuliah atau kehidupan pribadi menimbulkan motivasi kerja pada karyawan. Semakin baik work life balance atau keseimbangan kehidupan kerja yang dirasakan karyawan, hal tersebut juga akan mendorong karyawan bekerja lebih maksimal karena merasa kedua peran dapat dijalankan dengan seimbang. Pengaruh ini dapat terjadi karena beberapa faktor, seperti yang terlihat pada hasil kuesioner work life balance, yaitu pada item keseimbangan waktu memiliki nilai relatif tinggi, di mana menunjukkan karyawan memiliki keseimbangan waktu yang cukup untuk menjalankan kehidupan pribadi dan kehidupan kerja akibat jam kerja yang tidak lebih dari 40 jam perminggu, maupun jam lembur yang sesuai, sehingga menimbulkan peningkatan mutu kualitas kerja.

Berdasarkan karakteristik responden diketahui karyawan yang telah menikah atau berumah tangga lebih dominan. Di mana prioritas utama bagi karyawan yang telah menikah adalah keluarga, ketika kehidupan keluarga dapat berjalan dengan baik maka akan menimbulkan kebahagiaan yang akan menjadi motivasi untuk bekerja dan memenuhi target dari perusahaan. Seperti hasil wawancara yang dilakukan dengan Ibu N 45 tahun, menyatakan keseimbangan waktu yang diberikan oleh perusahaan terutama waktu untuk mengurus diri sendiri dan keluarga merupakan hal yang sangat penting. Menurutnya pekerjaan yang dilakukannya saat ini untuk kebahagiaan keluarganya, ketika mereka merasa tidak ada waktu dengan keluarga maka mereka lebih memilih untuk meninggalkan pekerjaan, terutama bagi ibu-ibu yang merasa tanggung jawab utamanya adalah anak dan suaminya.

Faktor lain yang menjadikan work life balance berpengaruh signifikan terhadap employee performance dapat dilihat dari karakteristik responden yang mana sebagian besar karyawan PDAM Giri Tirta Cabang Menganti masih dalam masa menempuh pendidikan perkuliahan baik S1 maupun S2. Bagi karyawan yang masih dalam tahap menempuh pendidikan pembagian waktu antara kerja dan kuliah lumayan sulit, terutama akibat adanya pandemi yang mana perkuliahan dilakukan secara online, dengan jadwal yang kadang lebih tidak beraturan dan kurang efektifnya perkuliahan terkadang menganggu jam kerja. Seperti hasil wawancara yang dilakukan dengan Pak W 24 tahun yang saat ini sedang menempuh pendidikan kuliah di salah satu universitas swasta di Gresik, menurutnya terkadang ia harus mengorbankan salah satu antara jadwal kuliah online yang bertabrakan dengan jam kerja. Selain ia terikat pada target perusahaan yang harus selesai, mereka juga terikat dengan tanggung jawab tugas kuliah. Tetapi menurutnya perusahaan telah memberikan waktu yang cukup fleksibel asal tetap dapat memenuhi target ketika bekerja meskipun pekerjaan tetap dilakukan pada jam kerja dan tidak bisa dilakukan di rumah. Hal ini memberikan keuntungan bagi ia dan rekannya yang memilih kuliah sambil bekerja meskipun terkadang kurang maksimal dalam menjalankan pendidikan karena harus membagi fokus untuk dua prioritas tugas. Sehingga dapat diketahui bahwa work life balance yang diberikan perusahaan untuk karyawan di PDAM Giri Tirta Kabupaten Gresik Cabang Menganti memengaruhi kinerja karyawan. Ketika work life balance yang dirasakan karyawan bagus maka hal tersebut juga akan berdampak meningkatkan employee performance, dan begitupun sebaliknya.

\section{Pengaruh Work Life Balance terhadap Job Satisfaction}

Hasil pengujian atau olah data menunjukkan bahwa work life balance berpengaruh signifikan positif terhadap job satisfaction, sehingga $\mathrm{H} 2$ diterima. Hasil ini mendukung penelitian Anuradha \& Pandey (2016) yang dilakukan pada dokter wanita di rumah sakit swasta Jharkhand dengan menggunakan variabel work life balance dan job satisfaction, bahwa work life balance berpengaruh signifikan positif terhadap job satisfaction. Anuradha \& Pandey (2016), mengungkapkan bahwa dokter yang 
dapat mengelola kehidupan kerja dan kehidupan keluarga dengan baik mereka cenderung lebih puas dan tidak mudah mengalami stres, hal ini dikarenakan tanggung jawab mereka yang semakin meningkat terutama dalam melayani pasien membuat tanggung jawab terhadap keluarga kadang terganggu dan berkurang ketika dijalankan secara bersamaan.

Berdasarkan hasil kuesioner work life balance yang telah disebarkan, nilai keseimbangan keterlibatan relatif tinggi, berupa kesempatan untuk melakukan kegiatan sosial di luar pekerjaan atau lingkungan rumah, dan keseimbangan kepuasan pada item rasa senang menjalani pekerjaan relatif tinggi, sehingga mengakibatkan kepuasan kerja karyawan juga cenderung meningkat. Peningkatan kepuasan kerja tersebut dapat dilihat pada hasil kuesioner job satisfaction yang telah disebar, yaitu item faktor psikologis memiliki nilai yang relatif tinggi.

Seperti hasil wawancara yang dilakukan dengan Ibu N 45 tahun sebelumnya, beliau menuturkan perusahaan sangat peduli dengan kebutuhan karyawannya terutama yang berhubungan dengan keseimbangan kehidupan kerja karyawan. Perusahaan memberikan kesempatan yang baik untuk selalu terlibat dalam lingkungan kerja maupun lingkungan pribadi atau keluarga, perusahaan juga memerhatikan kebutuhan karyawan mulai dari faktor fisik maupun psikologis misalnya dengan adanya jaminan kesehatan dan deskripsi pekerjaan yang jelas dan tidak begitu memberatkan. Sehingga karyawan dalam bekerja tidak merasa terbebani dan dapat melakukan pekerjaan semaksimal mungkin sesuai standar atau kualitas yang diharapkan perusahaan, yang mana hal tersebut menimbulkan kepuasan kerja. Maka dapat dijelaskan bahwa work life balance yang diberikan perusahaan PDAM Giri Tirta Kabupaten Gresik Cabang Menganti memiliki pengaruh positif dan signifikan terhadap job satisfaction karyawan.

\section{Pengaruh Job Satisfaction terhadap Employee Performance}

Hasil pengujian diketahui bahwa job satisfaction tidak memiliki pengaruh signifikan terhadap employee performance, sehingga H3 ditolak. Penelitian ini mendukung penelitian Bataineh (2019) pada karyawan industri farmasi di Yordania. Penelitian menggunakan variabel keseimbangan kehidupan kerja (work life balance), kebahagiaan di tempat kerja, keterlibatan karyawan, kepuasan kerja, komitmen organisasi yang efektif dan kinerja karyawan, diperoleh hasil bahwa job satisfaction atau kepuasan kerja tidak berpengaruh signifikan terhadap employee performance atau kinerja karyawan. Bataineh (2019) mengungkapkan faktor yang memengaruhi tingkat kinerja karyawan yaitu keseimbangan kehidupan kerja yang memudahkan karyawan dalam menjalankan tugasnya, kebahagiaan di tempat kerja seperti keterlibatan karyawan dan komitmen afektif organisasi dari karyawan.

Jika dihubungkan pada penelitian di PDAM Giri Tirta Kabupaten Gresik Cabang Menganti, ketika kepuasan kerja meningkat hal ini juga akan membuat kinerja meningkat, begitupun sebaliknya. Tetapi kepuasan kerja tersebut tidak dapat dijadikan faktor utama penentu peningkatan motivasi kerja karyawan. Seperti hasil wawancara yang dilakukan dengan karyawan bagian kasir Ibu R 23 tahun, ia menyatakan kepuasan kerja yang diberikan perusahaan menurutnya sedikit banyak memang dapat membantu karyawan bekerja lebih baik, tetapi terlepas dari itu rasa puas setiap orang menurutnya relatif berbeda-beda, puas menurutnya belum tentu puas menurut orang lain. Ia berpendapat bahwa keseimbangan kehidupan kerjalah yang lebih berperan penting dalam memengaruhi kinerja, karena meskipun karyawan merasa puas dengan pekerjaannya tetapi ketika tanggung jawab atau perannya di rumah tidak berjalan dengan baik maka hal tersebut juga akan memengaruhi konsentrasi pada saat bekerja yang akan berdampak pada kurang maksimalnya kinerja karyawan.

Pengaruh job satisfaction terhadap employee performance yang tidak signifikan juga dapat dianalisis dari hasil kuesioner job satisfaction, item faktor fisik memiliki nilai relatif sedang. Ini dikarenakan target kerja yang diberikan perusahaan terutama pada subbagian distribusi dan gangguan atau teknik lebih berat dibanding kan subbagian lain, sehingga kepuasan yang dirasakan cenderung berbeda. Hal tersebut dapat terlihat dari kepuasan yang dirasakan subbagian teknik pada jawaban kuesioner ratarata kurang terutama pada jam kerja yang tidak lebih 40 jam perminggu, ataupun jam lembur yang 
Mei Wulandari \& Hafid Kholidi Hadi. Peran Job Satisfaction sebagai Variabel Intervening antara Work Life Balance terhadap Employee Performance

tidak lebih dari 14 jam perminggu. Pada subbagian teknik atau distribusi dan gangguan beban pekerjaan mereka cukup berat, di mana mereka harus siap bekerja kapan saja ketika ada kebocoran pipa ataupun yang berhubungan dengan gangguan distribusi air pelanggan. Sehingga di luar jam kantor atau jam lembur pun, bahkan di saat hari libur biasanya mereka tetap dituntut siaga, karena sudah menjadi deskripsi pekerjaan mereka, dan hal tersebut memengaruhi tingkat kepuasan kerja kurang, meskipun demikian kinerja mereka tetap berusaha maksimal untuk melayani pelanggan. Kepuasan dinilai kurang tepat jika dihubungkan dengan pengaruhnya terhadap kinerja. Karena sekalipun pada subbagian pelayanan pelanggan kepuasan cukup tinggi, tetapi kepuasan yang dirasakan subbagian gangguan distribusi kurang, kinerja mereka sama-sama maksimal dan sesuai standar mutu perusahaan. Maka nilai hubungan job satisfaction terhadap employee performance kurang berpengaruh atau bahkan tidak menghasilkan pengaruh signifikan.

\section{Pengaruh Work Life Balance terhadap Employee Performance melalui Job Satisfaction}

Hasil pengujian menunjukkan bahwa pengaruh antara work life balance terhadap employee performance tidak dapat terjadi melalui job satisfaction, meskipun memiliki arah hubungan yang positif, sehingga $\mathrm{H} 4$ ditolak. Ini menunjukkan bahwa job satisfaction berperan berbanding lurus dengan peningkatan atau penurunan employee performance serta work life balance, Tetapi peran job satisfaction tersebut tidak bisa berpengaruh sebagai perantara terjadinya employee performance oleh work life balance.

Penelitian ini sejalan dengan penelitian Soomro et al. (2018), peran job satisfaction merupakan variabel moderasi, peran kepuasan kerja atau job satisfaction dapat mendukung untuk memerkuat ataupun memerlemah pengaruh work life balance terhadap employee performance. Ketika karyawan memiliki work life balance yang tinggi lalu didukung pula dengan kepuasan kerja yang tinggi, maka mereka akan mencapai kinerja tertinggi.

Hasil ini juga mendukung penelitian Mendis \& Weerakkody (2018) yang mana dalam arah hubungannya work life balance terhadap employee performance melalui job satisfaction memiliki arah hubungan positif. Penelitian tersebut menggunakan variabel work life balance, employee performance, dan job satisfaction pada pegawai tingkat eksekutif di industri telekomunikasi Sri Lanka, yang menunjukkan hasil bahwa work life balance apabila semakin baik maka peningkatan kinerja dan kepuasan kerja akan ikut meningkat.

Jika dikaitkan dengan penelitian di PDAM Giri Tirta Kabupaten Gresik Cabang Menganti, peran job satisfaction atau kepuasan kerja memang tidak memengaruhi signifikan kinerja karyawan atau employee performance, tetapi tetap mendukung besar kecilnya peningkatan kinerja seperti hasil kuesioner job satisfaction yang telah disebar, bahwa menunjukkan nilai relatif sedang, di mana kepuasan kerja yang dirasakan karyawan antar subbagian tidak dapat diukur dengan sama rata, sehingga kurang tepat jika dijadikan sebagai perantara hubungan antar variabel. Hal tersebut didukung pula dengan hasil wawancara sebelumnya yang dipaparkan oleh Ibu R 23 Tahun, bahwa faktor kepuasan setiap orang berbeda-beda. Terutama bagi karyawan yang ada pada subbagian distribusi gangguan atau teknik, di mana jam kerja mereka yang tidak normal bahkan lebih dari jam kerja pada umumnya dan jam lembur yang tidak terbatas menjadikan nilai atau faktor kepuasan yang mereka rasakan dan butuhkan berbeda dengan subbagian lain.

Karyawan yang memiliki kepuasan memang cenderung akan bekerja lebih semangat, tetapi karena kepuasan yang dirasakan tiap orang memiliki standar yang berbeda maka hal tersebut tidak dapat dijadikan dasar penentu utama. Hal ini didukung dengan pernyataan Ibu I 47 tahun, di mana menurutnya kepuasan yang sebenarya dapat dirasakan yaitu ketika urusan pribadi atau keluarga dapat berjalan dengan baik sehingga ketika bekerja bisa melakukannya dengan tenang tanpa terganjal masalah di rumah yang belum selesai. Karena para karyawan terutama bagi mereka yang berperan sebagai orang tua, prioritas utama mereka adalah anak atau keluarga dan pekerjaan yang mereka jalani juga semata untuk memenuhi kebutuhan keluarga mereka. 
Dengan kata lain bahwa yang memiliki peran penting dalam memengaruhi peningkatan kinerja karyawan yaitu adanya work life balance yang baik yang dirasakan karyawan, peran job satisfaction hanya pendukung saja yang dapat memperkuat pengaruh terhadap employee performance. Adanya job satisfaction pada karyawan di PDAM Giri Tirta Kabupaten Gresik Cabang Menganti tidak memberikan pengaruh sebagai perantara penentuan peningkatan employee performance yang disebabkan work life balance. Tetapi perannya dalam hubungan antar variabel lebih tepat sebagai variabel pendukung yang dapat membantu memerkuat ataupun memerlemah bukan sebagai variabel perantara seperti penelitian yang dihasilkan oleh Soomro et al. (2018). Peran penting work life balance terhadap employee performance lebih bisa berpengaruh secara langsung tanpa melibatkan kepuasan kerja karyawan. Ini karenakan sifat work life balance itu sendiri mutlak atau tidak terikat baik oleh status maupun bagian atau divisi apapun. Sesuai hasil beberapa wawancara yang dipaparkan diatas, semua karyawan membutuhkan work life balance yang tinggi, baik yang berstatus menikah dengan adanya prioritas keluarganya ataupun bagi sebagian mereka yang belum menikah tetapi dalam tahap menempuh pendidikan tinggi. Jika kedua peran antara kehidupan kerja juga kehidupan pribadi berjalan dengan seimbang maka hal tersebut juga akan memengaruhi karyawan secara fisik maupun psikologis untuk dapat memberikan performa terbaiknya dalam melakukan pekerjaan sesuai standar mutu yang ditetapkan perusahaan.

\section{KESIMPULAN}

Berdasarkan hasil pengujian, analisis data dan pembahasan yang sudah dipaparkan, maka dapat ditarik kesimpulan: pertama, work life balance berpengaruh signifikan positif terhadap employee performance. Hal tersebut menjelaskan bahwa apabila perusahaan PDAM Giri Tirta Kabupaten Gresik Cabang Menganti menerapkan work life balance yang baik kepada karyawan maka akan berdampak pada employee performance yang semakin meningkat; kedua, work life balance berpengaruh signifikan positif terhadap job satisfaction. Hal tersebut menunjukkan bahwa work life balance yang diberikan PDAM Giri Tirta Kabupaten Gresik Cabang Menganti kepada karyawan akan membuat job satisfaction karyawan meningkat; ketiga, job satisfaction tidak berpengaruh signifikan terhadap employee performance. Hal tersebut menunjukkan bahwa job satisfaction yang diberikan PDAM Giri Tirta Kabupaten Gresik Cabang Menganti tidak memiliki dampak pada employee performance; keempat, job satisfaction sebagai variabel intervening tidak memediasi hubungan antara work life balance terhadap employee performance. Artinya peran job satisfaction yang diberikan perusahaan PDAM Giri Tirta Kabupaten Gresik Cabang Menganti tidak dapat menjadi perantara work life balance memengaruhi employee performance.

Rekomendasi penelitian ini untuk dipertimbangkan perusahaan di antaranya: perusahaan diharapkan menyesuaikan kapasitas Sumber Daya Manusia (SDM) yang tersedia, dan memerhatikan pembagian jam kerja juga reward untuk motivasi karyawan agar tidak terlalu stres dan kelelahan dalam bekerja sehingga work life balance, job satisfaction, serta employee performance dapat terjaga. Sedangkan untuk penelitian selanjutnya diharapkan dapat lebih memerhatikan posisi divisi atau subbagian yang akan dijadikan sampel penelitian, hal tersebut akan membuat hasil riset lebih tepat sasaran dan memberikan hasil yang sesuai dengan hipotesis. Serta dapat mempertimbangkan variabel stres kerja ataupun kesehatan mental (mental health) pada penelitian selanjutnya, sehingga dapat memberikan gambaran lebih jelas dan memperkuat dampak dari hasil pengaruh work life balance terhadap job satisfaction maupun employee performance, dikarenakan dampak yang diberikan dari baik buruknya work life balance maupun job satisfaction seseorang sangat berpengaruh pada kecemasan, kegelisahan, dan sumber stres individu yang mana merupakan indikator dari kesehatan mental. Hal ini sesuai dengan Haar et al. (2013), bahwa work life balance dan job satisfaction berpengaruh signifikan negatif terhadap kecemasan individu, sehingga dapat dijelaskan bahwa ketika work life balance dan job satisfaction semakin baik maka kecemasan individu akan cenderung menurun, dengan kata lain kesehatan mental akan semakin baik. 
Mei Wulandari \& Hafid Kholidi Hadi. Peran Job Satisfaction sebagai Variabel Intervening antara Work Life Balance terhadap Employee Performance

\section{DAFTAR PUSTAKA}

Anuradha, \& Pandey, M. (2016). Impact of Work Life Balance on Job Satisfaction of Women Doctors. Problems and Perspectives in Management, 14(2), 319-324. https://doi.org/10.21511/ppm.14(2-2).2016.07

As’ad, M. (2004). Psikologi Industri Seri Ilmu SDM (Edisi 6). Yogyakarta: Liberty.

Auranzeb, \& Bhutto, S. A. (2016). Work Life Balance and Job Satisfaction: An Assessment of Pakistan's Banking Sector. Research on Humanities and Social Sciences, 6(18), 69-74. www.iiste.org

Bataineh, K. A. (2019). Impact of Work Life Balance, Happiness at Work, on Employee Performance. International Business Research, 12(2), 99-112. https://doi.org/10.5539/ibr.v12n2p99

Clark, S. (2000). Work Family Border Theory: A New Theory of Work Family Balance. Human Relations, 8(3), 1041-1068.

Dousin, O., Collins, N., \& Kler, B. K. (2019). Work Life Balance, Employee Job Performance and Satisfaction Among Doctors and Nurses in Malaysia. International Journal of Human Resource Studies, 9(4), 306-319. https://doi.org/10.5296/ijhrs.v9i4.15697

Fisher, G. G., Bulger, C. A., \& Smith, C. S. (2009). Beyond Work and Family: A Measure of Work /Nonwork Interference and Enhancement. Journal of Occupational Health Psychology, 441456.

Ganapathi, I. M. D. (2016). Pengaruh Work Life Balance terhadap Kepuasan Kerja Karyawan (Studi pada PT. Bio Farma Persero). Ecodemica, IV(1), 125-135. http://www.researchgate.net/publication

Greenhaus, J. H., Collins, K. M., \& Shaw, J. D. (2003). The Relation between Work Family Balance and Quality of Life. Journal of Vocational Behavior, 63(3), 510-531. https://doi.org/10.1016/S0001-8791(02)00042-8

Haar, J. M., Russo, M., Suñe, A., \& Ollier-Malaterre, A. (2013). Outcomes of Work Life Balance On Job Satisfaction, Life Satisfaction and Mental Health: a Study Across Seven Cultures. Journal of Vocational Behavior, 85(3), 1-36. https://upcommons.upc.edu/bitstream/handle/2117/24429/Outcomes of WLB across 7 cultures post-print.pdf

Hasibuan, M. S. (2003). Manajemen Sumber Daya Manusia. Jakarta: Bumi Angkasa.

Herlambang, H. C., \& Murniningsih, R. (2019). Pengaruh Work Life Balance terhadap Kinerja Karyawan dengan Kepuasan Kerja sebagai Variabel Intervening (Studi Empiris pada Serikat Pekerja Media dan Industri Kreatif Untuk Demokrasi (SINDIKASI)). Prosiding 2nd Business and Economics Conference In Utilizing of Modern Technology, 558-566. https://doi.org/10.1057/9781137309341.0019

Isse, H., Abdirahman, H., Najeemdeen, I. S., Abidemi, T., \& Ahmad, R. B. (2018). The Relationship between Job Satisfaction, Work Life Balance and Organizational Commitment on Employee Performance. IOSR Journal of Business and Management (IOSR-JBM), 20(5), 76-81. https://doi.org/10.9790/487X-2005077681

Keino, D. C., \& Kithae, P. P. (2016). Effects of Work Life Balance on Staff Performance in the Telecommunication Sector in Kenya. Archives of Business Research, 4(1), 129-138. 
Lockwood, N. R. (2003). Work Life Balance: Challenges and Solutions for Human Resource Management. SHRM Research, Research Quarterly, 1-10.

Luthans, F. (2011). Organizational Behaviour. New York: MC Graw Hill International Editions.

Mangkunegara, A. P. (2009). Manajemen Sumber Daya Manusia Perusahaan. Bandung: PT. Remaja Rosdakarya Bandung.

Machuca, M. M., Berbegal-Mirabent, J., \& Alegre, I. (2016). Work Life Balance and its Relationship with Organizational Pride and Job Satisfaction. Journal of Managerial Psychology, 31(2), 586602. https://doi.org/10.1108/JMP-09-2014-0272

Maslichah, N., \& Hidayat, K. (2017). Pengaruh Work Life Balance dan Lingkungan Kerja terhadap Kepuasan Kerja Karyawan (Studi pada Perawat RS Lavalette Malang Tahun 2016). Jurnal $\begin{array}{llllll}\text { Administrasi Bisnis } & \text { S1 } & \text { Universitas } & \text { Brawijaya, } & 49(1), & \end{array}$ administrasibisnis.studentjournal.ub.ac.id

Mathis, R. L., \& Jackson, J. H. (2006). Manajemen Sumber Daya Manusia (Edisi 9). Jakarta: Salemba Empat.

Mendis, M. D. V. S., \& Weerakkody, W. A. S. (2018). The Impact of Work Life Balance on Employee Performance with Reference to Telecommunication Industry in Sri Lanka: a Mediation Model. Kelaniya Journal of Human Resource Management, 12(1), 72-100. https://doi.org/10.4038/kjhrm.v12i1.42

Muliawati, T., \& Frianto, A. (2020). Peran Work Life Balance dan Kepuasan Kerja terhadap Kinerja Karyawan Milenial: Studi Literatur. Ilmu Manajemen, XX(2018), 606-620.

Nirmalasari, I. (2018). Analisis Pengaruh Work Life Balance terhadap Komitmen Organisasi melalui Kepuasan Kerja Perawat sebagai Mediator. Jurnal Ekonomi Dan Bisnis, 2(2).

Nurwahyuni, S. (2019). Pengaruh Beban Kerja terhadap Kinerja Karyawan melalui Work Life Balance (Studi Kasus PT. Telkom Indonesia Regional V). Jurnal Ilmu Manajemen (JIM), 7(1), $1-9$.

Obiageli, O. L., Uzochukwu, O. C., \& Ngozi, C. D. (2015). Work Life Balance and Employee Performance in Selected Commercial Banks in Lagos State. European Journal of Research and Reflection in Management Sciences, 3(4), 63-77.

Pathak, A. K., Dubey, P., \& Singh, D. (2019). Work Life Balance \& Job Satisfaction: A Literature Review International Journal of Computer Sciences and Engineering Open Access. International Journal of Computer Sciences and Engineering, 7(3), 182-187. https://doi.org/10.6084/m9.figshare.12016704

PDAM Giri Tirta. (2016). Tentang Giri Tirta. (http://pdam.gresikkab.go.id/hal-tentang-giri-tirta, diakses pada 10 Oktober 2020).

Rene, R., \& Wahyuni, S. (2018). Pengaruh Work-Life Balance terhadap Komitmen Organisasi, Kepuasan Kerja, dan Motivasi Kerja terhadap Kinerja Individu pada Karyawan Perusahaan Asuransi di Jakarta. Jurnal Manajemen dan Bisnis Sriwijaya, 16(1), 53-63. https://doi.org/10.29259/jmbs.v16i1.6247

Rivai, V. (2005). Manajemen Sumber Daya Manusia. Jakarta: PT. Raja Grafndo Persada.

Robbins, S. P., \& Judge, T. A. (2008). Perilaku Organisasi (Edisi 12). Jakarta: Salemba Empat. 
Mei Wulandari \& Hafid Kholidi Hadi. Peran Job Satisfaction sebagai Variabel Intervening antara Work Life Balance terhadap Employee Performance

Shoba D., \& Suganthi G. (2019). Work Life Balance and Job Satisfaction - A Structural Equation Modeling. GIS Business, 14(6), 1265-1272. https://doi.org/10.26643/gis.v14i6.11692

Sidik, R. (2019). Pengaruh Kemampuan, Work Life Balance, Kepuasan Kerja terhadap Kinerja Karyawan pada Karyawan BMT Permata Jawa Timur. Yos Soedarso Economics Journal, 1(1), 20-28.

Son, D. M., \& Jung, Y.-I. (2019). The Effect of Work Life Balance on Job Satisfaction and Turnover Intention of Hospital Nurses: Compared to Female Wage Workers. Stress, 27(3), 268-276. https://doi.org/10.17547/kjsr.2019.27.3.268

Soomro, A. A., Breitenecker, R. J., \& Shah, S. A. M. (2018). Relation of Work Life Balance, Work Family Conflict, and Family Work Conflict with the Employee Performance Moderating Role of Job Satisfaction. South Asian Journal of Business Studies, 7(1), 129-146. https://doi.org/10.1108/SAJBS-02-2017-0018

Susanto, M. (2019). Apa Itu Revolusi Industri 4.0? (https://www.zenius.net/blog/21104/revolusiindustri-4-0, diakses pada 09 Oktober 2020).

Undang-Undang RI. (2004). Undang-Undang Republik Indonesia Nomor 7 Tahun 2004 tentang Sumber Daya Air (pp. 1-110). (https://www.dpr.go.id/dokjdih/document/uu/7.pdf, diakses pada 10 Oktober 2020).

Wambui, M. L., Cherotich, B. C., Emily, T., \& Dave, B. (2017). Effects of Work Life Balance on Employees Performance in Institutions of Higher Learning. A Case Study of Kabarak University. Kabarak Journal of Research \& Innovation, 4(2), 60-79. http://eserver.kabarak.ac.ke/ojs/

Yuen, K. F., Loh, H. S., Zhou, Q., \& Wong, Y. D. (2018). Determinants of Job Satisfaction and Performance of Seafarers. Transportation Research Part A: Policy and Practice, 110, 1-12. https://doi.org/10.1016/j.tra.2018.02.006 